\title{
Endothelial effects of antihypertensive treatment: focus on irbesartan
}

\author{
Roberto Negro \\ Department of Endocrinology, \\ "V Fazzi" Hospital, Lecce Italy
}

\begin{abstract}
The endothelium is characterized by a wide range of important homeostatic functions. It participates in the control of hemostasis, blood coagulation and fibrinolysis, platelet and leukocyte interactions with the vessel wall, regulation of vascular tone, and of blood pressure. Many crucial vasoactive endogenous compounds are produced by the endothelial cells to control the functions of vascular smooth muscle cells and of circulating blood cells. These complex systems determine a fine equilibrium which regulates the vascular tone. Impairments in endotheliumdependent vasodilation lead to the so called endothelial dysfunction. Endothelial dysfunction is then characterized by unbalanced concentrations of vasodilating and vasoconstricting factors, the most important being represented by nitric oxide (NO) and angiotensin II (AT II). High angiotensin-converting enzyme (ACE) activity leads to increased AT II generation, reduced NO levels with subsequent vasoconstriction. The net acute effect results in contraction of vascular smooth muscle cells and reduced lumen diameter. Furthermore, when increased ACE activity is chronically sustained, increase in growth, proliferation and differentiation of the vascular smooth muscle cells takes place; at the same time, a decrease in the anti-proliferative action by NO, a decrease in fibinolysis and an increase in platelets aggregation may be observed. AT II is then involved not only in the regulation of blood pressure, but also in vascular inflammation, permeability, smooth muscle cells remodelling, and oxidative stress which in turn lead to atherosclerosis and increased cardiovascular risk. Given the pivotal role exerted by AT II in contributing to alteration of endothelial function, treatment with ACE inhibitors or angiotensin receptor blockers (ARBs) may be of particular interest to restore a physiological activity of endothelial cells. In this view, the blockade of the renin-angiotensin system (RAS), has been shown to positively affect the endothelial function, beyond the antihypertensive action displayed by these compounds. In this review, attention has been specifically focused on an ARB, irbesartan, to examine its effects on endothelial function.
\end{abstract}

Keywords: angiotensin-converting enzyme inhibitors, angiotensin receptor blockers, endothelial dysfunction, irbesartan

\section{Introduction}

The endothelium is a monolayer that covers the inner surface of the entire vascular system; its total weight is more than a liver, and if extended, it covers various tennis courts area. Other than being a barrier between blood and tissues, endothelial cells have multiple functional activities, that are impaired in common diseases like hypertension, diabetes, and the metabolic syndrome. The main feature of the endothelial dysfunction is an impaired endothelium-dependent vasodilation, that is mainly due to reduced nitric oxide (NO) availability and increased angiotensin II (AT II) levels. This altered balance induces an increase of oxidative stress, free radicals, inflammation, and coagulation. In this picture, the use of angiotensin-receptor blockers (ARBs) or angiotensin-converting enzyme inhibitors (ACEis), has demonstrated that these drugs display multiple beneficial effects on endothelial function; then, while in the past, the blood pressure control was considered the most important therapeutic target, 
nowadays these drugs have shown such favorable effects on the endothelial cells that these properties can not be considered just ancillary.

\section{Endothelial function}

Endothelial cells line the internal lumen of all the vasculature and serve as an interface between circulating blood and vascular smooth muscle cells. Other than being a physical barrier between blood and tissues, the endothelium displays multiple interactions with vascular smooth muscle cells and blood components. Then the endothelium cannot be considered just as a barrier, as it plays a pivotal role in vasculature function: it is involved in vasodilation and vasoconstriction, inflammation, regulation of the thrombotic state, proliferation, and apoptosis of vascular smooth muscle cells (Haller 1997; De Meyer and Herman 1997).

Among the functions of endothelial cells, the NO production is certainly one of the most important. NO is a free radical produced from an essential amino acid,
L-arginine, which in turn is converted in L-citrulline and subsequent production of NO (Palmer et al 1987) (Figure 1). This reaction is catalyzed by the endothelial NO synthase (eNOS). The physiologic event that leads to an increased activity of eNOS is represented by the shear stress, ie, the force produced by the blood flow per surface unit of the vascular wall (Vallance et al 1989). Once produced, NO diffusing in vascular smooth muscle cells, activates the guanylate cyclase (cGMP), which induces relaxation and then vasodilation. Other relevant effects of NO include inhibition of platelets activation, limitation of vascular smooth muscle cells proliferation, monocytes adhesion, platelets aggregation, and apoptosis of endothelial cells (Radomski et al 1987a; Garg and Hassid 1989). Other factors with vasodilating action are represented by prostacyclins and hyperpolarizing factor (EDHF). The prostacyclin $\mathrm{PGI}_{2}$ is the main prostaglandin produced by the endothelium; its functions are represented by vasodilation, inhibition of platelets aggregation, and inhibition of vascular smooth

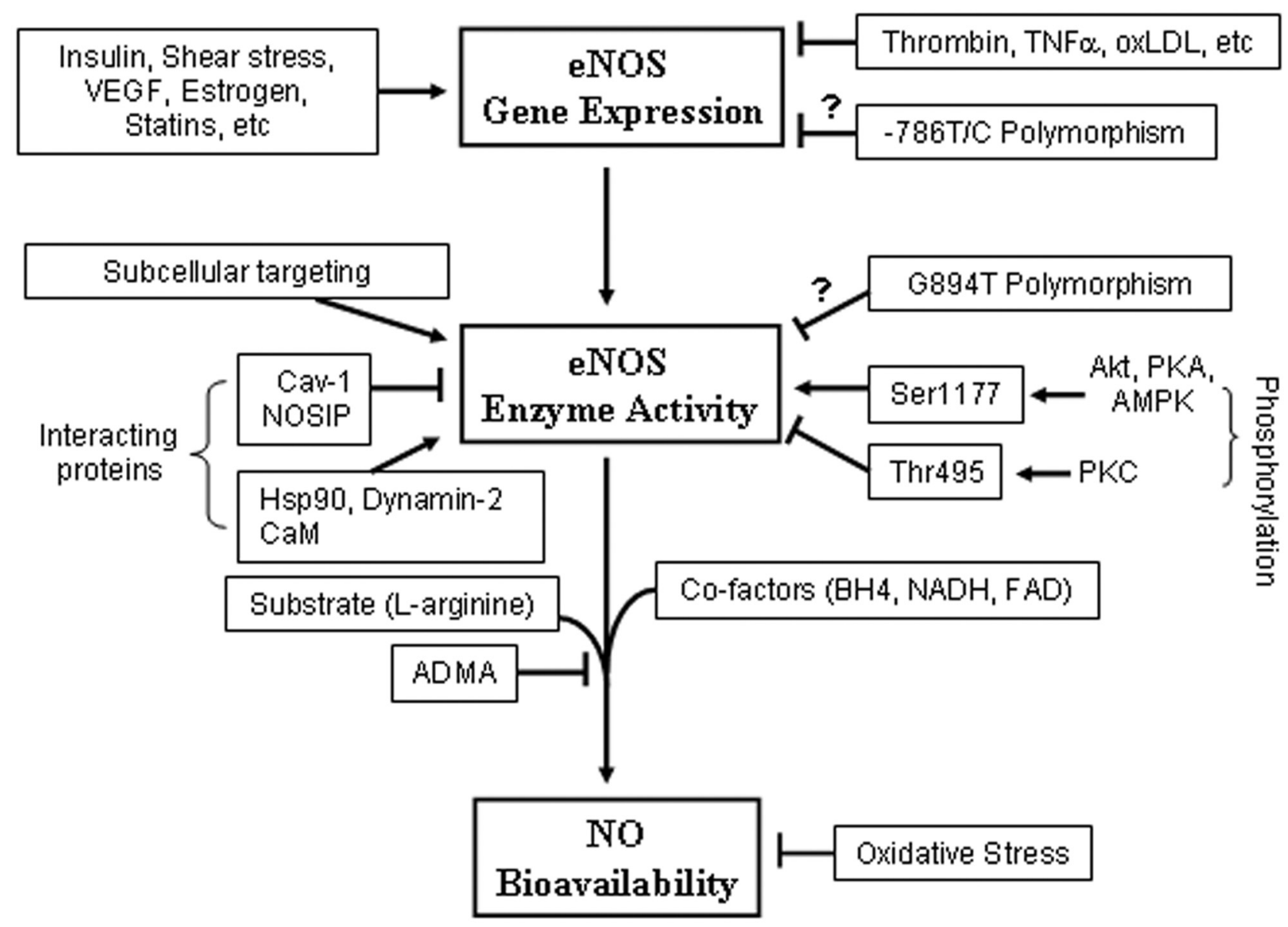

Figure I Regulatory mechanisms of endothelial NO production. Reproduced with permission from Yang Z, Ming XF. 2006. Recent advances in understanding endothelial dysfunction in atherosclerosis. Clin Med Res, 4:53-65. Copyright (C) 2006 Marshfield Clinic. 
muscle cells proliferation (Moncada and Higgs 1987). EDHF is an endothelium-derived factor which exerts a vasodilating action mainly on small vessels, and whose action is reduced in presence of diabetes (Chen et al 1988; Matsumoto et al 2003). As endothelial cells contribute to regulate the vascular tone, they are able to produce not only vasodilating but also vasoconstricting factors. AT II exerts opposite actions in respect to NO in the regulation of the vascular tone (Dzau 1989). AT II induces at vascular level proliferation and migration of smooth muscle cells; furthermore, it is involved in the production of reactive species of oxygen (ROS), such altering the NO mediated vasodilation (Luscher and Tanner 1993). AT II, other than determining the proliferation and migration of vascular smooth muscle cells, induces the expression of adhesion molecules and chemokines which mediate the adhesion and the migration of the monocytes in the vascular wall (Tummala et al 1999; Kintscher et al 2001). The key enzyme that regulates the local generation of AT II is the angiotensin-converting enzyme (ACE). This proteolytic enzyme is synthesized by the endothelial cells and exerts its activity upon the blood-borne angiotensin I. AT II binds to and regulates vascular smooth muscle cells tone via specific angiotensin receptors (Studdy et al 1983). Elevated ACE concentrations antagonize NO activity not only by increasing AT II generation but also by decreasing concentrations of bradykinin (Mombouli 1997). High ACE activity leads to vasoconstriction due to reduced NO levels and increased AT II generation. The net acute effect results in contraction of vascular smooth muscle cells and reduced lumen diameter. Furthermore, when increased ACE activity is chronically sustained, a stimulation of growth, proliferation, and differentiation of the vascular smooth muscle cells takes place; at the same time, a decrease in the antiproliferative action by NO, a decrease in fibinolysis and an increase in platelets aggregation may be observed. Another factor involved in vascular tone regulation is represented by endothelin-1 (ET-1) (Yanagisawa et al 1988). ET-1 induces vasodilation at low concentrations while vasoconstriction at high concentrations (Seo et al 1994). The interactions of ET-1 with its receptors, ETA and ETB, are responsible either for vasoconstriction, or induction of vascular smooth muscle cells proliferation (Arai et al 1990; Sakurai et al 1990). Other factors which display vasoconstricting properties are tromboxane $\mathrm{A}_{2}$ and prostaglandin $\mathrm{H}_{2}$, which represent products of the cyclooxygenase pathway. Both these factors exert actions which antagonize $\mathrm{NO}$ and prostacyclin activities not just at endothelial level but also at vascular smooth muscle cells and platelets level. Furthermore, the cyclooxygenase pathway represents a source of anion superoxide which in turn is a potent NO inactivator (Juliet et al 2003). Under physiologic conditions $\mathrm{PGI}_{2}$ and $\mathrm{NO}$ prevent platelets aggregation and adhesion to the endothelium, such underlining a key role exerted by the endothelial cells in the regulation of the coagulative state. Of note, NO inhibits monocytes adhesion to vascular wall, an event that triggers the development of atherosclerotic plaque (Böger et al 2000). Then, one of the actions exerted by endothelial cells concerns coagulation. Physiologically, the most important activator of the conversion of plasminogen to plasmin is the tissue plasminogen activator ( $\mathrm{t}-\mathrm{PA}$ ). This peptide has a critical role in the dissolution of clots and maintenance of vessel lumen. The most important regulator of t-PA is the plasminogen activator inhibitor-1 (PAI-1) (Dawson and Henney 1992). AT II is able to stimulate platelets aggregation and to induce a procoagulative state by the activation of PAI-1 expression (Vaughan et al 1995).

The endothelium is also involved in the production of specific molecules which may have a role in inflammation (Biegelsen and Loscalzo 1999). The most important are the intracellular adhesion molecule (ICAM) and vascular cell adhesion molecule (VCAM). These molecules act attracting and anchoring those cells involved in the inflammatory reaction. Not by chance, the atherosclerotic process is associated with increased levels of acute phase proteins (Tracy et al 1997).

\section{Endothelial dysfunction}

Endothelial dysfunction is characterized by a defect in endothelium-dependent vasodilation which precedes a series of structural changes of the vascular wall. It may occur at any level in the arterial system and contribute to the development and progression of atherosclerosis by favoring coagulation, cells adhesion, and inflammation, by promoting inappropriate vasoconstriction, and/or vasodilation, and by enhancing trans-endothelial transport of atherogenic lipoproteins. The main alteration ascribable to the endothelial dysfunction is a reduced (or absent) availability of $\mathrm{NO}$, essentially as a consequence of increased oxidative stress. The endothelial dysfunction may contribute to the onset and progression of atherosclerosis and several studies have reported that endothelial dysfunction represents an independent predictor of cardiovascular events not only at coronary district but also in peripheral vasculature (Perticone et al 2001; Gokce et al 2002).

Hypertension is a pathological condition which activates endothelial cells leading to the production of contracting 
factors, including thromboxane $\mathrm{A}_{2}$, prostaglandin $\mathrm{H}_{2}$, cyclooxigenase-derived endothelium-dependent contracting factors (ECDF), and oxygen free radicals, which antagonize the relaxing activity of NO (Miller and Vanhoutte 1985; Aldere et al 1986; Katusic and Vanhoutte 1989). Furthermore, oxygen free radicals can impair endothelial function by causing NO breakdown (Gryglewski et al 1986).

Endothelial dysfunction has been extensively explored by evaluating the response to pharmacological or mechanical endothelium-dependent stimuli (Lüscher and Noll 1996). Impaired response to acetylcholine, methacholine, bradykinin, and substance $\mathrm{P}$ has been documented in the forearm vasculature of essential hypertensive patients compared with normotensive controls (Linder et al 1990; Panza et al 1990; Panza et al 1993a, b, c; Taddei et al 1994; Creager and Roddy 1994; Panza et al 1995; Taddei et al 1995; Taddei et al 1997). Since in the same experimental conditions the vasodilating effect of an endothelium-independent vasodilator such as sodium nitroprussiate was found to be preserved, this line of evidence clearly indicates the presence of endothelial dysfunction in essential hypertension. Moreover, the evidence that reduced response to acetylcholine is detected in young normotensive offspring of essential hypertensive patients, and that this abnormality does not correlate with blood pressure levels, suggests that impaired endothelium-dependent vasodilation, may be at least in part, genetically determined (Taddei et al 1996). Both the animal and human data strongly suggest that the production of COX-dependent EDCF is one of the principal mechanisms leading to an impaired availability of NO, at least in aging or essential (spontaneous) hypertension. Therefore, endothelial dysfunction accompanied by the production of EDCF must play a key role in the progression of cardiovascular disease (Radomski et al 1987a, b; Dubey and Lucher 1993; Kubes et al 1991; De Caterina et al 1995). NO is an important autoregulatory inhibitor of inflammation (Napoli and Ignarro 2001). It limits oxidative stress in the microvasculature through its ability to scavenge ROS (Miles et al 1996). Noteworthy, even if the relationship between angiotensin receptors and NO is not fully clear, it has to be outlined that ACEis and ARBs exerted protective effects on AT II-mediated inflammatory response (Tamarat et al 2002; Chen et al 2003). Interestingly, there is accumulating evidence to suggest a central role for inflammatory response in the pathogenesis of endothelial dysfunction, hypertension, and coronary artery disease. Elevated C-reactive protein (CRP) and interleukin-6 (IL-6) levels have been shown to be related with a poor outcome in patients with unstable angina, probably reflecting an important inflammatory component in the pathogenesis of this condition (Liuzzo et al 1994; Liuzzo et al 2001). A large number of studies has demonstrated that AT II is involved in key events of the inflammatory process. AT II increases vascular permeability (by the release of prostaglandins and vascular endothelial cell growth factor or rearrangement of cytoskeletal proteins) that initiates the inflammatory process (Baylis and Brenner 1978; Ichikawa and Harris 1991; Schramek et al 1995). AT II contributes to the recruitment of inflammatory cells into the tissue through the regulation of adhesion molecules and chemokines by resident cells (Pastore et al 1999; Piqueras et al 2000; Pueyo et al 2000). Moreover, AT II could directly activate infiltrating immunocompetent cells, including chemotaxis, differentiation and proliferation (Diet et al 1996; Hansson 2001; Costantinescu et al 1998). Additional data suggest that RAS activation could play a certain role even in immunologicallyinduced inflammation (Rodriguez-Iturbe et al 2001). Finally, AT II participates in tissue repair and remodeling, through the regulation of cell growth and matrix synthesis (Egido 1996; Nakamura et al 2000; Tunon et al 2000; Border and Noble 2001; Wolf et al 2002). In summary, there are evidences enough to support the hypothesis that RAS is key mediator of inflammation. AT II is then involved not only in the regulation of blood pressure, but also in vascular inflammation, permeability, smooth muscle cells remodelling, and oxidative stress which lead to atherosclerosis and increase cardiovascular risk. While in the past, AT II was considered as a circulating factor, playing a central role in the regulation of blood pressure and electrolyte homeostasis, it has been later ascertained that non-ACE pathways exist and function to generate about $40 \%$ of the total AT II (Campbell 1987; Johnston 1992; Gibbons and Dzau 1994; Hollenberg et al 1998; Padmanabhan et al 1999). In fact, vascular inflammatory response has been shown to be more closely related to local AT II than circulating AT II, and recent studies tried to elucidate the consequences of increased AT II production within specific organs (heart, vasculature, pancreas, adipose tissue) (Bader et al 2001; Fleming et al 2006). These data indicate that there is a remarkable production of AT II by tissues and that a complete suppression of the RAS cannot be achieved by ACE inhibition alone (Petrie et al 2001). Inhibition of the RAS by blockade at the AT-1 receptor should, theoretically, result in more complete inhibition of the adverse cardiovascular effects of AT II. On the other hand, ACEis also inhibit the enzyme kininase II, which is responsible for the degradation of bradykinin (Erdos 1975) (Figure 2). Several studies have emphasized the possible role of elevated bradykinin levels resulting from ACE inhibitor therapy. 
Favorable hemodynamic effects mediated by bradykinin may include venodilation, vasodilation (coronary and systemic), improved left ventricular relaxation, and contractile function (Trippodo et al 1995; Hornig et al 1998; Cheng 1998).

Other potential benefits of bradykinin include a reduction in ventricular dilatation and cardiac hypertrophy, an increase in levels of endogenous tissue plasminogen activator, and an improvement in abnormal endothelial function (Mancini et al 1996; Schlaifer et al 1997). An additional evidence of the importance of the bradykinin system in ACE inhibition comes from a study by Guazzi et al (1997). The authors showed that although losartan and enalapril had similar hemodynamic and clinical effects, the action of enalapril was antagonized by aspirin, whereas that of losartan was not. This may be related to the role of the bradykinin in mediating prostaglandin release. But bradykinin has been blamed for some of the undesirable complications of ACEis such as cough and angioedema. Cough may occur in up to $10 \%$ of patients treated with ACEis, while angioedema represents a potentially lethal complication (Israili and Hall 1992; Fox et al 1996). By directly blocking AT-1 receptors, ARBs can inhibit the action of AT II while having little or no effect on the bradykinin system (Brooks and Ruffolo 1999).

Hypertension is a common condition which is often associated with obesity, diabetes, and dyslipidemia. There is much evidence in support of an activation of the RAS in obesity. This has led to the notion that blockade of the RAS might be a beneficial strategy for management of hypertension associated with obesity (Sharma 2004). Adipose RAS has recently received much attention because experimental

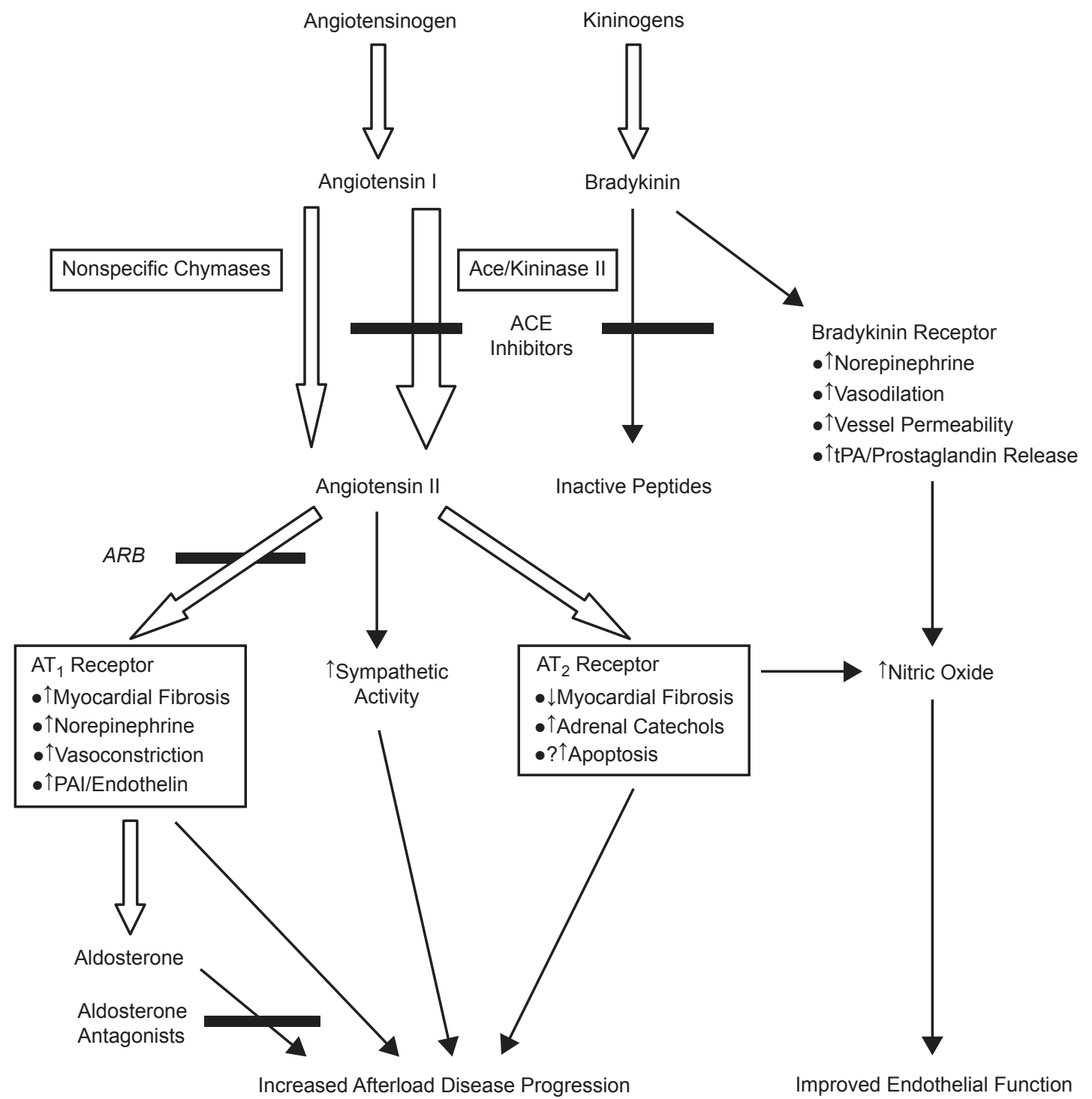

Figure 2 Relationships between angiotensin and kinin cascades. 
evidence has shown its involvement in the pathophysiology of obesity-induced hypertension. In mice, adipocyte-derived angiotensinogen can act locally to affect adipocyte growth and differentiation and can also be secreted into the bloodstream, contributing to the circulating pool of angiotensinogen (Massiera et al 2001). The demonstration that angiotensinogen produced by the adipose tissue may be released in the bloodstream suggests that the high circulating levels of angiotensinogen associated with obesity may be attributable in part to increased fat mass. Mice with obesity induced by a high-fat diet exhibit greater angiotensinogen gene expression in intra-abdominal fat but not in other fat depots or non-adipose tissues (Rahmouni et al 2004). Interestingly, increased production of angiotensinogen by intraabdominal fat appears to explain the high circulating levels of this peptide observed in dietary obesity (Boustany et al 2004). Activation of adipose RAS is also involved in development of high blood pressure in transgenic mice used as a model of visceral obesity. These transgenic mice show an increase in enzyme activity similar to that seen in obese humans and replicate visceral fat accumulation and high blood pressure (Masuzaki et al 2003). The hypertension observed in this model was abolished by selective AT receptor blockade. The above-mentioned data establish that adipose RAS plays an important role in the association between obesity and hypertension. This activation of adipose RAS may also explain the link between excessive visceral fat and cardiovascular diseases. Endothelial dysfunction is a typical feature of the states of insulin resistance and not by chance, and obesity is associated with elevated plasma levels of ET-1 (Steinberg et al 1996; Ferri et al 1996). Caballero et al (1999) demonstrated early abnormalities in vascular reactivity and biochemical markers of endothelial cells activation in individuals at risk of developing diabetes. The investigators measured the increase in blood flow in the microcirculation (laser Doppler flowmetry) and in the macrocirculation (ultrasound) in four groups of subjects: 1) healthy normoglycemic individuals with no history of type 2 diabetes in a first-degree relative (controls); 2) healthy normoglycemic subjects with a history of type 2 diabetes in one or both parents; 3 ) subjects with impaired fasting glucose; and 4) patients with type 2 diabetes without vascular complications. Moreover the investigators measured plasma concentrations of ET-1, soluble intercellular adhesion molecule (sICAM), and soluble vascular cell adhesion molecule (sVCAM), as indicators of endothelial cells activation. The vasodilatatory responses to acetylcholine were reduced in groups 2, 3, and 4 compared with controls and ET-1 was significantly higher in these three groups. These results suggest that abnormalities in vascular reactivity and biochemical markers of endothelial cells activation are present early in individuals at risk of developing type 2 diabetes, even at stage when normal glucose tolerance exists. Hyperglycemia can cause endothelial dysfunction not only in already diagnosed diabetes but also in mild and transient increases of blood glucose, as demonstrated in studies carried on healthy volunteers undergoing hyperglycemic clamp (Williams et al 1998). The crucial point that determines endothelial dysfunction, without structural alterations of the vascular wall, is the reduced availability of NO. Insulin exerts its vascular effects primarily by increasing the availability of NO. In experimental conditions of insulin resistance, endothelial-mediated vasodilation is impaired, because of insulin's inability to stimulate the activity of eNOS (Vincent et al 2003; Shaul 2002). In the presence of diabetes, several factors may alter NO availability: increased production of oxygen free radicals, increased levels of asymmetric dimethylarginine (ADMA), which is an irreversible inhibitor of NOS, activation of protein-kinase C (PKC), and accelerated production of advanced products of glycosilation (AGEs) (Brownlee 1992; Surdacki et al 2007). Since 1992, ADMA has been recognized as an endogenous inhibitor of eNOS, and in vitro experiments demonstrated that the NO production is inhibited by ADMA in a concentration-dependent manner (Vallance et al 1992). In fact, ADMA represents a cardiovascular risk factor: it is a strong predictor of cardiovascular events and total mortality in hemodialysis patients; high ADMA concentrations are related to increased risk of death in patients on intensive care unit, and it predicts the outcome after percuteneous coronary intervention in patients with stable angina pectoris (Zoccali et al 2001; Nijveldt et al 2003; Lu et al 2003). It has become more and more evident that the production of free oxygen radicals plays a pivotal role in the development of vascular complications of diabetic disease (Ceriello 2006). In vitro studies suggest that endothelial cells exposed to high glucose levels increase the production of superoxide and show alterations of the cell proliferation, which may be completely prevented by the increase in the expression of endogenous anti-oxidants (Nishikawa et al 2000; Zanetti et al 2001). Diabetic patients are particularly exposed to the endothelial damage from free radicals also because they show a reduction of anti-oxidant defences, including a reduction of superoxide dismutase (Crouch et al 1978). Another important mediator of endothelial dysfunction in diabetes is represented by the activation of PKC. In presence of hyperglycemia high levels of diacylglycerol activate PKC which in turn induces alterations of eNOS activity and 
NADPH oxidase, and then contributes to an elevated production of free oxygen radicals and to an increase in oxidative stress (Hink et al 2001). NADPH is required for proper NO generation; hyperglycemia may lead to intracellular changes in the redox state with activation of PKC resulting in depletion of the cellular NADPH pool (Williamson et al 1993). If acute hyperglycemia induces endothelial dysfunction mostly by worsening oxidative stress, chronic hyperglycemia exerts further deleterious effects on vascular wall by production of AGEs. It has been demonstrated that in the presence of diabetes, AGEs accumulation is able to inhibit NO production producing defective endothelium-dependent vasodilation (Bucala et al 1991). Furthermore, the binding of AGEs with their cell receptors, receptors for advanced glycation endproducts (RAGE) and AGE-R3, may induce endothelial activation with consequent production of growth factors and pro-inflammatory molecules, which lead to development and progression of atherosclerotic process (Kislinger et al 2001). The inflammatory component in diabetic patients is particularly harmful, given the progression towards atherosclerosis. Proinflammatory cytokines, like tumor necrosis factor- $\alpha$ (TNF- $\alpha$ ), inhibit insulin-stimulated activation and expression of eNOS resulting in diminished levels of NO (Kim et al 2001; Anderson et al 2004). In vitro studies have demonstrated that CRP, which is particularly elevated in diabetic patients, induces direct damage at the endothelial level leading to a reduction in $\mathrm{NO}$ and vasodilating prostaglandins and an increase in ET-1. Furthermore, proinflammatory cytokines like TNF- $\alpha$ and IL- 6 have demonstrated a detrimental effect at the endothelial level (Picchi et al 2006). In humans, the relationships between inflammation, endothelial dysfunction, and hyperglycemia were outlined in the Hoorn Study, a population-based cohort study. Results showed that type 2 diabetes was associated with both endothelial dysfunction and low-grade inflammation, whereas impaired glucose tolerance was associated only with low-grade inflammation. These findings were independent of other risk factors that accompany diabetes. Furthermore, endothelial dysfunction and low-grade inflammation were associated with a greater risk of cardiovascular mortality, especially in diabetic patients; and, finally, diabetes-associated endothelial dysfunction and low-grade inflammation explained about $43 \%$ of the greater cardiovascular mortality risk conferred by type 2 diabetes (de Jager et al 2006). Not by chance, diabetic patients with myocardial infarction, compared with non-diabetic patients, show impaired endothelium-dependent vasodilation, lower adiponectin levels, and higher concentrations of TNF$\alpha$ and IL-6 (Nystrom et al 2006). Therefore, not only obesity, but also diabetes, are associated with proinflammatory states characterized by increased circulating markers of inflammation as well as infiltration of adipose tissue with activated macrophages (Weisberg et al 2003; Xu et al 2003). In particular, CRP has been identified as a risk factor for developing type 2 diabetes, and its levels are correlated with cardiovascular risk (Pradhan et al 2001; Saito et al 2003) (Figure 3).

\section{Effects of irbesartan on endothelial dysfunction}

In vitro and in vivo studies have explored the effects of ARBs on endothelial dysfunction. One of the most studied ARB is irbesartan, whose action has been proven to be beneficial in ameliorating endothelial function above all in hypertension and diabetes, two frequent diseases in which alterations of endothelium homeostasis are typically present. In essential hypertensive patients, treatment with irbesartan promoted a significant increase in endothelium-dependent and endothelium-independent vasodilation. In a study performed by Bragulat et al (2003), hypertensive patients were examined at baseline and at the end of a 6-month period of irbesartan treatment. Endothelium-dependent and endothelium-independent responses were determined by measuring changes in forearm blood flow (FBF) in response to intrarterial infusions of acetylcholine (endothelium-dependent vasodilation [EDV]), sodium nitroprusside (endotheliumindependent vasodilation [EIV]), with and without the addition of the NO synthase inhibitor L-NMMA. Irbesartan promoted a significant increase in EDV and EIV. L-NMMAinduced vasoconstriction was significantly enhanced after irbesartan treatment. Plasma concentrations of endothelin fell significantly after irbesartan treatment. In addition to a significant increase in endothelium-dependent and endothelium-independent vasodilation, irbesartan restored the vasoconstriction capacity of NO synthase inhibitors, suggesting a direct effect on tonic NO release, and decreased endothelin production. These actions may play an important role in the vascular protecting effects of irbesartan. One of the crucial points in the use of antihypertensive drugs concerns their beneficial effects beyond the reduction of blood pressure. Given the pivotal role that AT II exerts in determining endothelial dysfunction, it is reasonable that ACEis and ARBs may have some additive and favorable effects on endothelium. For example, when irbesartan has been compared with the beta-blocker atenolol, results have shown that both were able to improve endothelium-dependent vasodilation, but only irbesartan was able to reduce fibrinogen, PAI-1, 


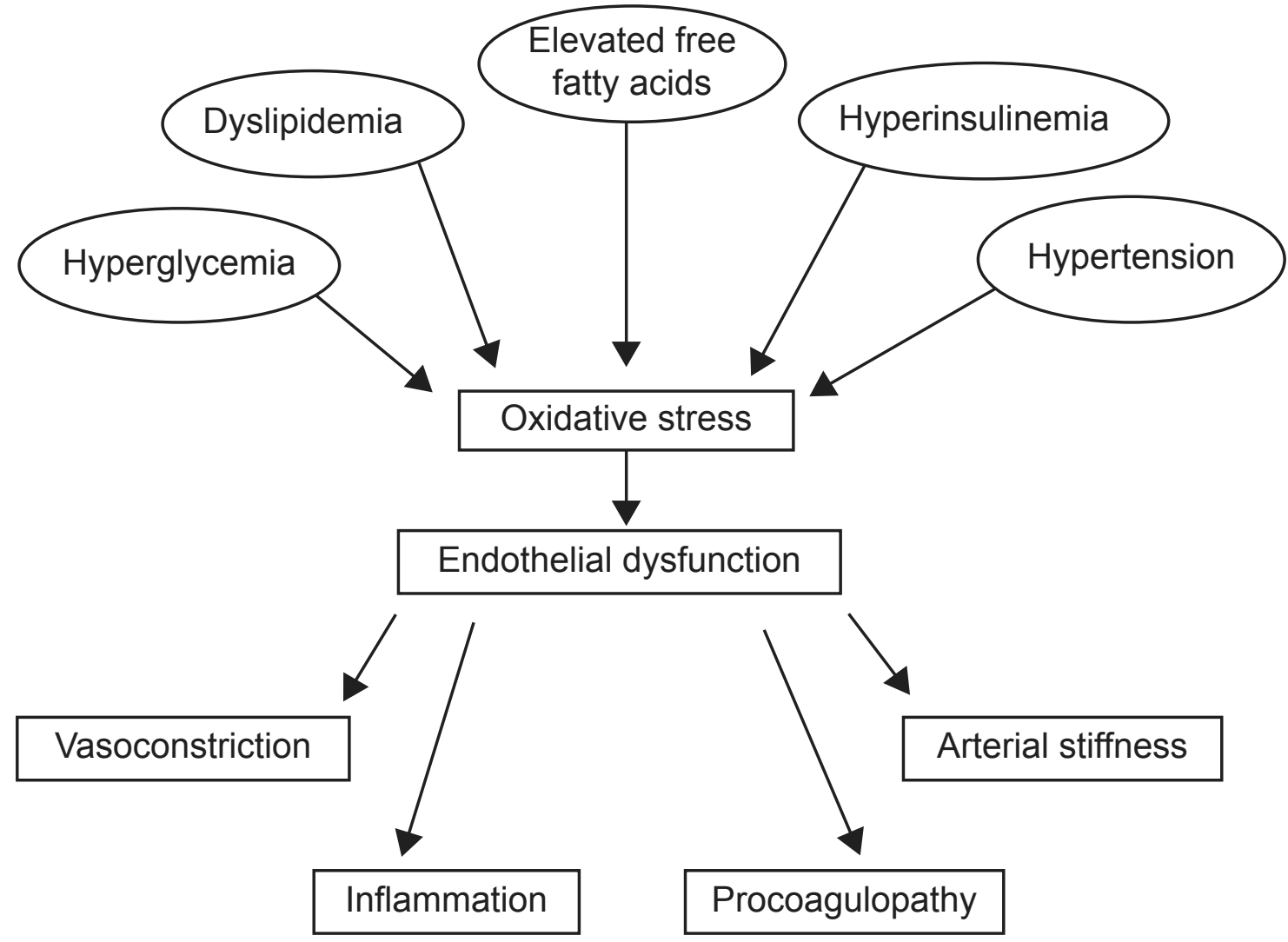

Figure 3 Factors contributing to endothelial dysfunction in type 2 diabetes.

and thrombomodulin. These results showed that, despite an equally controlled blood pressure, the ARB treatment was associated with a more favorable modification of hemostatic/ fibinolytic status (Makris et al 2000; von zur Muhlen et al 2001). The hypothesis that the blockade of AT-1 receptor may exert a protective effect on vasculature was also tested in a study that compared equihypotensive doses of irbesartan and amlodipine in apolipoprotein E-null mice, rendered diabetic by streptozotocin. Diabetes was associated with an increase in plaque area and complexity in the aorta, in association with a significant increase in aortic AT-1 receptor expression, cellular proliferation, collagen content, and macrophage-positive and alpha-smooth muscle actin-positive cell infiltration, as well as an increased expression of platelet-derived growth factor-B (PDGF-B), monocyte chemoattractant protein-1 (MCP-1), and vascular cell adhesion molecule-1 (VCAM-1). Irbesartan but not amlodipine treatment attenuated the development of atherosclerosis, collagen content, cellular proliferation, and macrophage infiltration as well as diabetes-induced AT-1 receptor, PDGF-B, MCP-1, and VCAM-1 overexpression in the aorta, despite similar blood pressure reductions by both treatments (Candido et al
2004). It has been also demonstrated that irbesartan exerts a favorable effect on vascular inflammation, which is a feature of endothelial dysfunction and promotes the development of atherosclerosis. In diabetic patients, irbesartan $300 \mathrm{mg}$ /day alone or in combination with atorvastatin $40 \mathrm{mg}$ /day was able to significantly increase flow-mediated dilatation while decreasing nitrotyrosine, CRP, ICAM-1, and IL-6; these beneficial effects on endothelial function were more marked when irbesartan was associated with atorvastatin (Ceriello et al 2005). The effects on vascular inflammation in type 2 diabetic patients were further assessed in the IRMA 2 substudy, a 2-year, multicenter, randomized, double-blind trial which compared irbesartan ( 150 or $300 \mathrm{mg} /$ day) versus placebo. A subgroup $(n=269)$ was analyzed for biomarkers of inflammatory activity at baseline and after 1 and 2 years. In this substudy, irbesartan was able to reduce markers of inflammatory activity, ie, CRP and fibrinogen; IL-6 showed a $1.8 \%$ increase per year compared with a $6.5 \%$ increase for placebo, and changes in IL-6 were associated with changes in albumin excretion. There was no treatment effect on the other biomarkers (ICAM, VCAM, E-selectin, trasforming growth factor- $\beta$, and AGEs). Then, in this study, irbesartan 
(300 mg/day) reduced low-grade inflammation in diabetic patients, possibly reducing the risk of micro- and macrovascular disease (Persson 2006). The ISLAND study (Irbesartan and Lipoic Acid in Endothelial Dysfunction) evaluated the ability of irbesartan and lipoic acid, an antioxidant, to affect endothelial function and inflammation in patients with the metabolic syndrome. Treatment with irbesartan significantly ameliorated the endothelium-dependent vasodilation by $67 \%$, treatment with lipoic acid by $44 \%$, and combined treatment by $75 \%$. In this study the two drugs reduced markers of inflammation such as IL-6 and PAI-1, while just irbesartan significantly reduced plasma levels of isoprostane-8, a marker of oxidative stress. Of note, these results were independent of blood pressure values, underlining the direct effects of AT-1 receptor blockade (Sola et al 2005). The increased cardiovascular risk encountered by women during the menopause is associated with endothelial dysfunction. It has been demonstrated that in ovariectomized rats, estrogen replacement therapy prevents endothelial dysfunction, and that irbesartan exerts a similar protective action, reducing oxidative stress and increasing NO availability (Wassmann et al 2001; Riveiro et al 2002). Of particular interest are the studies concerning the effects of ARBs on myocardial vasculature. One study evaluated the effect of irbesartan on the coronary and peripheral endothelial function in patients with coronary artery disease (CAD). Blockade of AT-1 receptor significantly improved flow-mediated dilation (FMD) of the brachial artery, while no changes in the coronary district were observed (Warnholtz et al 2006). It has to be noted that even if no significant improvement in coronary endothelial function was detected, since reduced FMD of the brachial artery is associated with high cardiovascular event rate, improvement of FMD may lead to better the prognosis in patients with CAD (Brevetti et al 2003). Two studies investigated endothelial function in congestive heart failure (CHF). In the first, treatment either with trandolapril or irbesartan significantly improved endothelium-dependent relaxation in rat aortic rings, but just the ARB was able to reduce superoxide aortic formation (Schäfer et al 2004). In the second, left and right ventricular (LV and RV) coronary vasodilatation reserve (CVR) were investigated in rats with hypertension or CHF. Results showed that treatment with irbesartan had no early effects on LV and RV CVR, and improved RV CVR over the long term, mainly by limiting RV hypertrophy and by preventing the development of pericoronary fibrosis and coronary endothelial function (Richer et al 2001). Taken together these results lead to the conclusion that irbesartan treatment can ameliorate endothelial function not only in peripheral vasculature, but also in the coronary district, ie, that these properties have a cardiovascular protective effect beyond blood pressure reduction.

\section{Perspectives and conclusions}

Recent studies have addressed the fundamental role exerted by the endothelial progenitor cells (EPCs) in endothelial function and cardiovascular risk. EPCs are bone-marrow derived cells which are responsible for vascular repair (Kocher et al 2001). It was observed a strong correlation between the number of circulating EPCs and the subjects' combined Framingham risk factor score. Measurement of flow-mediated brachial-artery reactivity also revealed a significant relation between endothelial function and the number of progenitor cells, and the levels of circulating EPCs were a better predictor of vascular reactivity than was the presence or absence of conventional risk factors. In addition, endothelial progenitor cells from subjects at high risk of cardiovascular events had higher rates of in vitro senescence than cells from subjects at low risk (Hill et al 2003). Therefore, reduced EPCs concentrations are associated with endothelial dysfunction, and, most important, their levels represent a strong predictor for the occurrence of cardiovascular events and death from cardiovascular causes (Werner et al 2005). In patients with high cardiovascular risk such as diabetic patients, the number and/or function of EPCs is significantly altered, and importantly, EPCs' proliferation is inversely related to HbA1c levels and duration of diabetes (Tepper et al 2002). Therefor, the chance of improving the number and/or function of EPCs represents a new frontier in the treatment of endothelial dysfunction. Just one study evaluated the effects of ARBs on EPCs. Bahlmann et al (2005) studied the effect of two ARBs, olmesartan and irbesartan, on the number of EPCs in diabetic patients. The main findings of this study were that EPCs were reduced in diabetic patients compared with healthy controls, and just 4 weeks' treatment with ARBs significantly increased the number of EPCs. This evidence suggest that the stimulatory action on EPCs number may be of therapeutic relevance and may help explain the beneficial effects of ARBs in preventing cardiovascular disease.

In conclusion, the pathophysiological basis of endothelial dysfunction outlines the crucial role exerted in particular by AT II and NO and the related increased risk of cardiovascular diseases. Studies globally agree on the protective effects induced by the blockade of RAS, and many of them involved irbesartan, demonstrating its beneficial actions beyond the blood pressure control. In vitro and in vivo studies, in fact, have confirmed that other than the classical and well known 
cardiovascular risk factors such as hypertension, cellular and molecular mechanism involving endothelial cells are pivotal for the development of atherosclerosis and coronary artery disease. The most recent discoveries help to explain and confirm the cardiovascular protective effect derived from irbesartan treatment, and at the same time open new and fascinating perspectives of care.

\section{References}

Aldere RJ, Kiritsy-Roy JA, Catravas JD. 1986. Acetylcholine-induced contractions in isolated rabbit pulmonary arteries: Role of thromboxane A2. J Pharmacol Exp Ther, 236:535-41.

Anderson HD, Rahmutula D, Gardner DG. 2004. Tumor necrosis factoralpha inhibits endothelial nitric-oxide synthase gene promoter activity in bovine aortic endothelail cells. J Biol Chem, 279:963-9.

Arai H, Hori S, Aramori I, et al. 1990. Cloning and expression of a cDNA encoding an endothelin receptor. Nature, 348:730-2.

Bader M, Peters J, Baltatu O, et al. 2001. Tissue renin-angiotensin systems: new insights from experimental animal models in hypertension research. J Mol Med, 79:76-102.

Bahlmann FH, de Groot K, Mueller O, et al. 2005. Stimulation of endothelial progenitor cells: a new putative therapeutic effect of angiotensin II receptor antagonists. Hypertension, 45:526-9.

Baylis C, Brenner BM. 1978. Modulation by prostaglandin synthesis inhibitors of the action of exogenous angiotensin II on glomerular ultrafiltration in the rat. Circ Res, 43:889-98.

Biegelsen ES, Loscalzo J. 1999. Endothelial function and atherosclerosis. Coron Artery Dis, 10:241-56.

Böger RH, Bode-Böger SM, Tsao PS, et al. 2000. An endogenous inhibitor of nitric oxide synthase regulates endothelial adhesiveness for monocytes. $J$ Am Coll Cardiol, 36:2287-95.

Border WA, Noble NA. 2001. Maximizing hemodynamic-independent effects of angiotensin II antagonists in fibrotic diseases. Semin Nephrol, 21:563-72.

Boustany CM, Bharadwaj K, Daugherty A, et al. 2004. Activation of the systemic and adipose renin-angiotensin system in rats with diet-induced obesity and hypertension. Am J Physiol, 287:R943-R9.

Bragulat E, Larousse M, Coca A, et al. 2003. Effect of long-term irbesartan treatment on endothelium-dependent vasodilation in essential hypertensive patients. Br J Biomed Sci, 60:191-6.

Brevetti G, Silvestro A, Schiano V, et al. 2003. Endothelial dysfunction and cardiovascular risk prediction in peripheral arterial disease: additive value of flow-mediated dilation to ankle-brachial pressure index. Circulation, 108:2093-8.

Brooks DP, Ruffolo RR Jr. 1999. Pharmacological mechanism of angiotensin II receptor antagonists: implications for the treatment of elevated systolic blood pressure. J Hypertens, 17(Supp1):S27-S32.

Brownlee M. 1992. Glycation products and the patogenesis of diabetic complications. Diabetes Care, 15:1835-53.

Bucala R, Tracey KJ, Cerami A. 1991. Advanced glycosylation products quench nitric oxide and mediate defective endothelium-dependent vasodilatation in experimental diabetes. J Clin Invest, 87:432-8.

Caballero AE, Arora S, Saouaf R, et al. 1999. Microvascular and macrovascular reactivity is reduced in subjects at risk for type 2 diabetes. Diabetes, 48:1856-62

Candido R, Allen TJ, Lassila M, et al. 2004. Irbesartan but not amlodipine suppresses diabetes-associated atherosclerosis. Circulation, 109:1536-42.

Campbell DJ. 1987. Circulating and tissue angiotensin systems. J Clin Invest, 79:1-6.

Ceriello A. 2006. Oxidative stress and diabetes-associated complications. Endocr Pract, 12(Suppl 1):60-2.
Ceriello A, Assaloni R, Da Ros R, et al. 2005. Effect of atorvastatin and irbesartan, alone and in combination, on postprandial endothelial dysfunction, oxidative stress, and inflammation in type 2 diabetic patients. Circulation, 111:2518-24.

Chen G, Suzuki H, Weston AH. 1988. Acetylcholine releases endotheliumderived hyperpolarizing factor and EDRF from rat blood vessels. $\mathrm{Br} J$ Pharmacol, 95:1165-74.

Chen R, Iwai M, Wu L, et al. 2003. Important role of nitric oxide in the effect of angiotensin-converting enzyme inhibitor imidapril on vascular injury. Hypertension, 42:542-7.

Cheng CP, Onishi K, Ohte N, et al. 1998. Functional effects of endogenous bradykinin in congestive heart failure. $J \mathrm{Am}$ Coll Cardiol, 31:1679-86.

Costantinescu CS, Goodman DB, Ventura ES. 1998. Captopril and lisinopril suppress production of interleukin-12 by human peripheral blood mononuclear cells. Immunol Lett, 62:25-31.

Creager MA, Roddy MA. 1994. Effect of captopril and enalapril on endothelial function in hypertensive patients. Hypertension, 24:499-505.

Crouch R, Kimsey G, Priest DG, et al. 1978. effect of streptozotocin on erythrocyte and retinal superoxide dismutase. Diabetologia, 15:53-7.

Dawson S, Henney A. 1992. The status of PAI-1 as a risk factor for arterial and thrombotic disease: a review. Atherosclerosis, 95:105-17.

De Caterina R, Libby P, Peng HB, et al. 1995. Nitric oxide decreases cytokine-induced endothelial activation. J Clin Invest, 96:60-8.

de Jager J, Dekker JM, Kooy A, et al. 2006. Endothelial dysfunction and low-grade inflammation explain much of the excess cardiovascular mortality in individuals with type 2 diabetes: the Hoorn Study. Arterioscler Thromb Vasc Biol, 26:1086-93.

De Meyer GR, Herman AG. 1997. Vascular and endothelial dysfunction. Prog Cardiovasc Dis, 39:325-42.

Diet F, Pratt RE, Berry GJ, et al. 1996. Increased accumulation of tissue ACE in human atherosclerotic coronary artery disease. Circulation, 94:2756-67.

Dubey OB, Lücher TF. 1993. Nitric oxide inhibits angiotensin II induced migration of vascular smooth muscle cells. Hypertension, $22: 412$

Dzau VJ. 1989. Short- and long-term determinants of cardiovascular function and therapy: contributions of circulating and tissue renin-angiotensin systems. J Cardiovasc Pharmacol, 14:S1-5.

Egido J. 1996. Vasoactive hormones and renal sclerosis. Kidney Intern, 49:578-97.

Erdos EG. 1975. Angiotensin I converting enzyme. Circ Res, 36:247-55.

Esper RJ, Vilariño JO. 2004. La disfunción endotelial. In: Esper RJ ed. Aterotrombosis en el tercer milenio. Barcelona: Prous Sciences. pp 49-83.

Ferri C, Bellini C, Desideri G, et al. 1996. Circulating endothelin-1 levels in obese patients with the metabolic syndrome. Exp Clin Endocrinol Diabetes, 105:38-40.

Fleming I, Kohlstedt K, Busse R. 2006. The tissue renin-angiotensin system and intracellular signalling. Curr Opin Nephrol Hypertens, $15: 8-13$.

Fox AJ, Lalloo UG, Belvisi MG, et al. 1996. Bradykinin-evoked sensitization of airway sensory nerves: a mechanism for ACE-inhibitor cough. Nat Med, 2:814-17.

Garg UC, Hassid A. 1989. Nitric oxide-generating vasodilators and 8-bromo-cyclic guanosine monophosphate inhibit mitogenesis and proliferation of cultured rat vascular smooth muscle cells. $J$ Clin Invest, 83:1774-7.

Gibbons GH, Dzau VJ. 1994. The emerging concept of vascular remodeling. N Engl J Med, 19:1431-38.

Gokce N, Keaney JF, Hunter LM, et al. 2002. Risk stratification for post-operative cardiovascular events via non-invasive assessment of endothelial function a prospective study. Circulation, 105:1567-72.

Gryglewski RJ, Palmer RMJ, Moncada S. 1986. Superoxide anion is involved in the breakdown of endothelium-derived vascular relaxing factor. Nature, 320:454-6. 
Guazzi M, Melzi G, Agostoni P. 1997. Comparison of changes in respiratory function and exercise oxygen uptake with losartan versus enalapril in congestive heart failure secondary to ischemic or idiopathic dilated cardiomyopathy. Am J Cardiol, 80:1572-6.

Haller H. 1997. Endothelial function. General considerations. Drugs, 53:1-10.

Hansson GK. 2001. Immune mechanisms in atherosclerosis. Arterioscler Thromb Vasc Biol, 21:1876-90.

Hill JM, Zalos G, Halcox JP, et al. 2003. Circulating endothelial progenitor cells, vascular function, and cardiovascular risk. $N$ Engl $J$ Med, 348:593-600.

Hink U, Li H, Mollnau H, et al. 2001. Mechanisms underlying endothelial dysfunction in diabetes mellitus. Circ Res, 88:14-22.

Hollenberg NK, Fisher ND, Price DA. 1998. Pathways for angiotensin II generation in intact human tissue: evidence from comparative pharmacological interruption of the renin system. Hypertension, 32:387-92.

Hornig B, Arakawa N, Drexler H. 1998. Effect of ACE inhibition on endothelial dysfunction in patients with chronic heart failure. Eur Heart $J$, 19(Suppl G):G48-G53.

Ichikawa I, Harris RC. 1991. Angiotensin actions in the kidney: renewed insight into the old hormone. Kidney Int, 40:583-96.

Israili ZH, Hall WD. 1992. Cough and angioneurotic edema associated with angiotensin-converting enzyme inhibitor therapy: a review of the literature and pathophysiology. Ann Intern Med, 117:234-42.

Johnston CI. 1992. Franz Volhard Lecture. Renin-angiotensin system: a dual tissue and hormonal system for cardiovascular control. J Hypertens (Suppl 10):S13-S26.

Juliet PA, Hayashi T, Iguchi A, et al. 2003. Concomitant production of nitric oxide and superoxide in human macrophages. Biochem Biophys Res Commun, 310:367-70.

Katusic ZS, Vanhoutte PM. 1989. Superoxide anion is an endotheliumderived contracting factor. Am J Physiol, 257:H33-7.

Kim F, Gallis B, Corson MA. 2001. TNF-alpha inhibits flow and insulin signaling leading to NO production in aortic endothelial cells. $A m J$ Physiol, 280:1057-65.

Kintscher U, Wakino S, Kim S, et al. 2001. Angiotensin II induces migration and Pyk2/paxillin phosphorylation of human monocytes. Hypertension, 37:587-93.

Kislinger T, Tanji N, Wendt T, et al. 2001. Receptor for advanced glycation end products mediates inflammation and enhanced expression of tissue factor in vasculature of diabetic apolipoprotein E-null mice. Arterioscler Thromb Vasc Biol, 2:905-10.

Kocher AA, Schster MD, Szabolcs MJ, et al. 2001. Neovascularization of ischemic myocardium by human bone-marrow-derived angioblasts prevents cardiomyocyte apoptosis, reduce remodelling and improves cardiac function. Nat Med, 7:430-6.

Kubes P, Suzuki M, Granger DN. 1991. Nitric oxide: an endogenous modulator of leucocyte adhesion. Proc Natl Acad Sci USA, 88:4651-5.

Linder L, Kiowski W, Buhler FR, et al. 1990. Indirect evidence for the release of endothelium-derived relaxing factor in the human forearm circulation in vivo: Blunted response in essential hypertension. Circulation, 81:1762-7.

Liuzzo G, Biasucci LM, Gallimore JR, et al. 1994. The prognostic value of C-reactive protein and serum amyloid a protein in severe unstable angina. $N$ Engl J Med, 331:417-24.

Liuzzo G, Angiolillo DJ, Buffon A, et al. 2001. Enhanced response of blood monocytes to in vitro lipopolysaccharide-challenge in patients with recurrent unstable angina. Circulation, 103:2236-41.

Lu T M, Ding YA, Lin SJ, et al. 2003. Plasma levels of asymmetrical dimethylarginine and adverse cardiovascular events after percutaneous coronary intervention. Eur Heart J, 24:1912-19.

Lüscher TF, Tanner FC. 1993. Endothelial regulation of vascular tone and growth. Am J Hypertens, 6:S283-93.

Lüscher TF, Noll G. 1996. Endothelial function as an end-point in interventional trials: concepts, method and current data. J Hypertens, 14(Suppl 2):S111-21.
Napoli C, Ignarro LJ. 2001. Nitric oxide and atherosclerosis. Nitric Oxide, 5:88-97.

Makris TK, Stavroulakis GA, Krespi PG, et al. 2000. Fibrinolytic/hemostatic variables in arterial hypertension: response to treatment with irbesartan or atenolol. Am J Hypertens, 13:783-8.

Mancini GB, Henry GC, Macaya C, et al. 1996. Angiotensin-converting enzyme inhibition with quinapril improves endothelial vasomotor dysfunction in patients with coronary artery disease: the TREND (Trial on Reversing ENdothelial Dysfunction) Study. Circulation, 94:258-65.

Massiera F, Bloch-Faure M, Ceiler D, et al. 2001. Adipose angiotensinogen is involved in adipose tissue growth and blood pressure regulation. FASEB J, 15:2727-9.

Masuzaki H, Yamamoto H, Kenyon CJ, et al. 2003. Transgenic amplification of glucocorticoid action in adipose tissue causes high blood pressure in mice. J Clin Invest, 112:83-90.

Matsumoto T, Kobayashi T, Kamata K. 2003. Alterations in EDHF-type relaxation and phosphodiesterase activity in mesenteric arteries from diabetic rats. Am J Physiol Heart Circ Physiol, 285:H283-91.

Miles AM, Bohole DS, Glassbrenner PA, et al. 1996. Modulation of superoxide-dependent oxidation and hydroxylation reactions by nitric oxide. J Biol Chem, 271:40-7.

Miller VM, Vanhoutte PM. 1985. Endothelium-dependent contractions to arachidonic acid are mediated by products of cyclooxygenase. Am J Physiol, 248:H432-7.

Mombouli JV. 1997. ACE inhibition, endothelial function and coronary artery lesions. Role of kinins and nitric oxide. Drugs, 54:12-22.

Moncada S, Higgs EA. 1987. Prostaglandins in the pathogenesis and prevention of vascular disease. Blood Rev, 1:141-5.

Nakamura S, Nakamura I, Ma L, et al. 2000. Plasminogen activator inhibitor-1 expression is regualted by the angiotensin type 1 receptor in vivo. Kidney Int, 58:251-9.

Nijveldt RJ, Teerlink T, van der Hoven B, et al. 2003. Asymmetrical dimethylarginine (ADMA) in critically ill patients: high plasma ADMA concentration is an independent risk factor of ICU mortality. Clin Nutr, 22:23-30.

Nishikawa T, Edelstein D, Du XL, et al. 2000. normalizing mitochondrial superoxide production blocks three pathways of hyperglycaemic damage. Nature, 404:787-90.

Nystrom T, Nygren A, Sjoholm A. 2006. Increased levels of tumour necrosis factor-alpha (TNF-alpha) in patients with Type II diabetes mellitus after myocardial infarction are related to endothelial dysfunction. Clin Sci (Lond.), 110:673-81.

Padmanabhan N, Jardine AG, McGrath JC, et al. 1999. Angiotensinconverting enzyme-independent contraction to angiotensin I in human resistance arteries. Circulation, 99:2914-20.

Palmer RM, Ferrige AG, Moncada S. 1987. Nitric oxide release accounts for the biological activity of endothelium-derived relaxing factor. Nature, 327:524-6.

Panza JA, Quyyumi AA, Brush JE Jr, et al. 1990. Abnormal endothelium dependent vascular relaxation in patients with essential hypertension. N Engl J Med, 323:22-7.

Panza JA, Casino PR, Kilcoyne CM, et al. 1993a. Role of endothelium-derived nitric oxide in the abnormal endothelium-dependent vascular relaxation of patients with essential hypertension. Circulation, 87:1468-74. .

Panza JA, Casino PR, Badar DM, et al. 1993b. Effect of increased availability of endothelium-derived nitric oxide precursor on endotheliumdependent vascular relaxation in normal subjects and in patients with essential hypertension. Circulation, 87:1475-81.

Panza JA, Quyyumi AA, Callahan TS, et al. 1993c. Effect of antihypertensive treatment on endothelium-dependent vascular relaxation in patients with essential hypertension. J Am Coll Cardiol, 21:1145-51.

Panza JA, Garcia CE, Kilcoyne CM, et al. 1995. Impaired endothelium dependent vasodilation in patients with essential hypertension. Evidence that nitric oxide abnormality is not localized to a single signal transduction pathway. Circulation, 91:1732-8. 
Pastore L, Tessitore A, Martinetti S, et al. 1999. Angiotensin II stimulates intracellular adhesion molecole-1 (ICAM-1) expression by human vascular endothelial cells and increases soluble ICAM-1 release in vivo. Circulation, 100:1646-52.

Persson F, Rossing P, Hovind P, et al. 2006. Irbesartan treatment reduces biomarkers of inflammatory activity in patients with type 2 diabetes and microalbuminuria: an IRMA 2 substudy. Diabetes, 55:3550-5.

Perticone F, Ceravolo R, Pujia A, et al. 2001. Prognostic significance of endothelial dysfunction in hypertensive patients. Circulation, 104:191-6.

Petrie MC, Padmanabhan N, McDonald JE, et al. 2001. Angiotensin converting enzyme (ACE) and non-ACE dependent angiotensin II generation in resistance arteries from patients with heart failure and coronary heart disease. J Am Coll Cardiol, 37:1056-61.

Picchi A, Gao X, Belmadani S, et al. 2006. Necrosis factor-alpha induces endothelial dysfunction in the prediabetic metabolic syndrome. Circ Res, 99:69-77.

Piqueras L, Kubes P, Alvarez A, et al. 2000. Angiotensin II induces leukocyteendothelial cell interactions in vivo via $\mathrm{AT}(1)$ and AT82) receptormediated P-selectin upregulation. Circulation, 102:2118-23.

Pradhan AD, Manson JE, Rifai N, et al. 2001. C-reactive protein, interleukin 6, and risk of developing type 2 diabetes mellitus. JAMA, 286:327-34.

Pueyo ME, Gonzalez W, Nicoletti A, et al. 2000. Angiotensin II stimulates endothelial vascular cell adhesion molecule-1 via nuclear factor-kappaB activation induced by intracellular oxidative stress. Arterioscler Thromb Vasc Biol, 20:645-51.

Radomski MW, Palmer RM, Moncada S. 1987a. The anti-aggregating properties of vascular endothelium: interactions between prostacyclin and nitric oxide. Br J Pharmacol, 92:639-46.

Radomski MW, Palmer RMJ, Moncada S. 1987b. Endogenous nitric oxide inhibits human platelet adhesion to vascular endothelium. Lancet, 2:1057-68.

Rahmouni K, Mark AL, Haynes WG, et al. 2004. Adipose depot-specific modulation of angiotensinogen gene expression in diet-induced obesity. Am J Physiol, 286:E891-E5.

Richer C, Domergue V, Gervais M, et al. 2001. Coronary dilatation reserve in experimental hypertension and chronic heart failure: effects of blockade of the renin-angiotensin system. Clin Exp Pharmacol Physiol, 28:997-1001

Riveiro A, Mosquera A, Alonso M, et al. 2002. Angiotensin II type 1 receptor blocker irbesartan ameliorates vascular function in spontaneously hypertensive rats regardless of oestrogen status. J Hypertens, 20:1365-72.

Rodriguez-Iturbe B, Pons H, Herrera-Acosta J, et al. 2001. Role of immunocompetent cells in nonimmune renal disease. Kidney Int, $59: 1626-40$

Saito M, Ishimitsu T, Minami J, et al. 2003. Relations of plasma highsensitivity C-reactive protein to traditional cardiovascular risk factors. Atherosclerosis, 167:73-9.

Sakurai T, Yanagisawa M, Takuwa Y, et al. 1990. Cloning of a cDNA encoding a non-isopeptide-selective subtype of the endothelin receptor. Nature, 348:732-5.

Schäfer A, Fraccarollo D, Tas P, et al. 2004. Endothelial dysfunction in congestive heart failure: ACE inhibition vs. angiotensin II antagonism. Eur J Heart Fail, 6:151-9.

Schlaifer JD, Wargovich TJ, O'Neill B, et al. for the TREND Investigators. 1997. Effects of quinapril on coronary blood flow in coronary artery disease patients with endothelial dysfunction. Am J Cardiol, 80:1594-7.

Schramek H, Coroneos E, Dunn MJ. 1995. Interactions of the vasoconstrictor peptides, angiotensin II and endothelin-1, with vasodilatory prostaglandins. Semin Nephrol, 15:195-204.

Seo B, Oemar BS, Siebenmann R, et al. 1994. Both ETA and ETB receptors mediate contraction to endothelin-1 in human blood vessels. Circulation, 89:1203-8

Sharma AM. 2004. Is there a rationale for angiotensin blockade in the management of obesity hypertension? Hypertension, 44:12-19.

Shaul PW. 2002. Regulation of endothelial nitric oxide synthase: location, location, location. Annu Rev Physiol, 64:749-74.
Sola S, Mir MQS, Cheema FA, et al. 2005. Irbesartan and acid lipoic improve endothelial function and reduce markers of inflammation in the metabolic syndrome. Results of the Irbesartan and Lipoic Acid in Endothelial Dysfunction (ISLAND) Study. Circulation, 111:343-8.

Steinberg HO, Chaker H, Leaming R, et al. 1996. Obesity/insulin resistance is associated with endothelial dysfunction. Implications for the syndrome of insulin resistance. $J$ Clin Invest, 97:2601-10.

Studdy PR, Lapworth R, Bird R. 1983. Angiotensin-converting enzyme and its clinical significance-a review. J Clin Pathol, 36:938-47.

Surdacki A, Stochmal E, Szurkowska M, et al. 2007. Nontraditional atherosclerotic risk factors and extent of coronary atherosclerosis in patients with combined impaired fasting glucose and impaired glucose tolerance. Metabolism, 56:77-86.

Taddei S, Mattei P, Virdis A, et al. 1994. Effect of potassium on vasodilation to acetylcholine in essential hypertension. Hypertension, 23: 485-90.

Taddei S, Virdis A, Ghiadoni L, et al. 1997. Cyclooxygenase inhibition restores nitric oxide activity in essential hypertension. Hypertension, 29:274-9.

Taddei S, Virdis A, Mattei P, et al. 1995. Aging and endothelial function in normotensive subjects and essential hypertensive patients. Circulation, 91:1981-7.

Taddei S, Virdis A, Mattei P, et al. 1996. Defective L-arginine nitric oxide in offspring of essential hypertensive patients. Circulation, 94:1298-303.

Tamarat R, Silvestre JS, Durie M, et al. 2002. Angiotensin II angiogenic effect in vivo involves vascular endothelial growth factor and inflammation-related pathways. Lab Invest, 82:747-56.

Tepper OM, Galiano RD, Capla JM, et al. 2002. Human endothelial progenitor cells from type II diabetics exhibit impaired proliferation, adhesion, and incorporation into vascular structures. Circulation, 106:2781-6.

Tracy RP, Lemaitre RN, Psaty BM, et al. 1997. Relationship of C-reactive protein to risk of cardiovascular disease in the elderly. Results from the Cardiovascular Health Study and the Rural Health Promotion Project. Arterioscler Thromb Vasc Biol, 17:1121-7.

Trippodo NC, Panchal BC, Fox M. 1995. Repression of angiotensin II and potentiation of bradykinin contribute to the synergistic effects of dual metalloprotease inhibition in heart failure. J Pharmacol Exp Ther, 272:619-27.

Tummala PE, Chen XL, Sundell CL, et al. 1999. Angiotensin II induces vascular cell adhesion molecule-1 expression in rat vasculature: a potential link between the renin-angiotensin system and atherosclerosis. Circulation, 100:1223-9.

Tunon J, Ruiz-Ortega M, Egido J. 2000. Regulation of matrix proteins and impact on vascular structure. Curr Hypertens Rep, 2:106-13.

Vallance P, Collier J, Moncada S. 1989. Effects of endothelium-derived nitric oxide on peripheral arteriolar tone in man. Lancet, 336:997-1000.

Vallance P, Leone A, Calver A, et al. 1992. Accumulation of an endogenous inhibitor of NO synthesis in chronic renal failure. Lancet, 339:572-5

Vaughan DE, Lazos SA, Tong K. 1995. Angiotensin II regulates the expression of plasminogen activator inhibitor-1 in cultured endothelial cells. A potential link between the rennin-angiotensin system and thrombosis. J Clin Invest, 95:995-1001.

Vincent MA, Barrett EJ, Lindner JR, et al. 2003. Inhibiting NOS blocks microvascular recruitment and blunts muscle glucose uptake in response to insulin. Am J Physiol Endocrinol Metab, 285:E123-9.

von zur Muhlen B, Kahan T, Hagg A, et al. 2001. Treatment with irbesartan or atenolol improves endothelial function in essential hypertension. J Hypertens, 19:1813-8.

Warnholtz A, Ostad MA, Heitzer T, et al. 2006. AT1-receptor blockade with irbesartan improves peripheral but not coronary endothelial dysfunction in patients with stable coronary artery disease. Atherosclerosis.

Wassmann S, Bäumer AT, Strehlow K, et al. 2001. Endothelial dysfunction and oxidative stress during estrogen deficiency in spontaneously hypertensive rats. Circulation, 103:435-41.

Weisberg SP, McCann D, Desai M, et al. 2003. obesity is associated with macrophage accumulation in adipose tissue. J Clin Invest, 112:1796-1808 
Werner N, Kosiol S, Schiegl T, et al. 2005. Circulating endothelial progenitor cells and cardiovascular outcomes. N Engl J Med, 353:999-1007.

Williams SB, Goldfine AB, Timimi FK, et al. 1998. Acute hyperglicemia attenuates endothelium-dependent vasodilation in humans in vivo. Circulation, 97:1695-701.

Williamson JR, Chang K, Frangos M, et al. 1993. Hyperglycemic pseudohypoxia and diabetic complications. Diabetes, 42:801-13.

Wolf G, Wenzel U, Burns KD, et al. 2002. Angiotensin II activates nuclear transcription factor-kappaB through AT1 and AT2 receptors. Kidney Int, 61:1986-95.

Xu H, Barnes GT, Yang Q, et al. 2003. Chronic inflammation in fat plays a crucial role in the development of obesity-related insulin resistance. $J$ Clin Invest, 112:1821-30.

Yanagisawa M, Kurihara H, Kimura S, et al. 1988. A novel potent vasoconstrictor peptide produced by vascular endothelial cells. Nature, 332:411-5.

Yang Z, Ming XF. 2006. Recent advances in understanding endothelial dysfunction in atherosclerosis. Clin Med Res, 4:53-65.

Zanetti M, Zwacka R, Engelhard J, et al. 2001. Superoxide anions and endothelial cells proliferation in normoglycemia and hyperglycemia. Arterioscler Thromb Vasc Biol, 21:195-200.

Zoccali C, Bode-Böger SM, Mallamaci F, et al. 2001. Asymmetric dimethylarginine (ADMA): an endogenous inhibitor of nitric oxide synthase predicts mortality in end-stage renal disease (ESRD). Lancet, 358:2113-17. 
